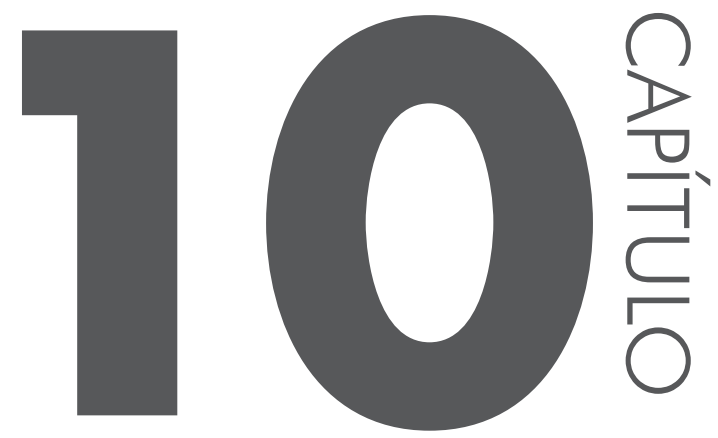

\title{
(RE)PRODUÇÃO DO ESPAC̣O URBANO E MERCADO IMOBILIÁRIO: A OFERTA DE TERRENOS URBANOS E IMÓVEIS RESIDENCIAIS EM ITUIUTABA-MG
}

Luciana Domingues Chaves José Vieira Neto

Resumo: Este artigo foi escrito para apresentar de modo parcial os resultados obtidos, no âmbito da pesquisa de mestrado com título provisório “(Re)produção do espaço urbano e mercado imobiliário: a oferta de terrenos urbanos e imóveis residenciais em Ituiutaba-MG”, que se encontra em desenvolvimento no âmbito do Programa de Pós-graduação da Universidade Federal de Goiás - Regional Catalão, 
cujo objetivo central consiste em compreender a (re)produção do espaço urbano em Ituiutaba-MG sob a ótica do mercado imobiliário. A abordagem recai na análise da dinâmica imobiliária a partir das ofertas de terrenos não edificados e, imóveis residenciais para venda (casas), anunciadas no principal jornal de circulação diária de Ituiutaba. O recorte temporal adotado correspondeu aos anos de 2000, 2005 e 2012, dos quais foram extraídos os anúncios, compreendidos no primeiro sábado dos meses de janeiro a dezembro. Diante da tabulação e organização dos dados em planilhas do software Microsoft Excel® somada à bibliografia estudada, notou-se de maneira genérica mudanças na (re)produção do espaço urbano de Ituiutaba-MG, ligadas a inter-relação dos fatores a) localização dos anúncios; b) preço ofertado em reais e c) seletividade espacial, de modo a destacar determinadas áreas da cidade no tocante a potencial valorização imobiliária.

Palavras-chave: (Re)produção do espaço urbano. Mercado imobiliário. Terrenos urbanos. Imóveis residenciais. Ituiutaba-MG.

Abstract: This article was written to present a partial way the results until, under the master's search with title provisional "(Re)production of space urban and real estate market: the supply of urban land and properties residences in Ituiutaba-MG, under development within the Pós-graduação da Universidade Federal de Goiás/Regional Catalão, whose goal is to understand (re)production of urban space in Ituiutaba-MG from the perspective of real estate market. The approach lies in the analysis of the real estate dynamics through land not built and , residential real estate for sale (houses), contained in the main daily newspaper of Ituiutaba. The adopted time frame corresponded to the years 2000, 2005 and 2012, ads were extracted, on the first Saturday of the months from January to December. With the tabulation and organization of data in spreadsheets Microsoft Excel ${ }^{\circledR}$ software plus the studied literature, we noticed generic changes in (re) production of urban space Ituiutaba-MG linked the interrelationship of factors a) location of ads; b) offered price in reais and c) spatial selectivity in order to highlight certain areas of the city with regard to potential real estate appreciation.

Keywords: (Re)production of urban space. Real estate market. Urban land. Residential real estate. Ituiutaba-MG.

\section{INTRODUC̣ÃO}

Os estudos urbanos em torno do papel do mercado imobiliário e do poder público têm ganhado na última década suma importância para a compreensão da produção. Acredita-se que isto decorre do momento econômico atual em que o Brasil se encontra, destacando-se no estímulo ao consumo, no aumento de subsídios ao crédito, nos financiamentos, em eventos esportivos como Copa do Mundo de 2014 e Jogos Olímpicos de 2016. Assim, a principal discussão que se faz 
na pesquisa se refere ao espaço urbano; especificamente, ao seu processo de (re) produção no âmbito do mercado imobiliário. Fruto de um processo dinâmico, Corrêa (2005) compreende o espaço urbano como produto social delineado pela atuação dos seguintes agentes: a) os proprietários dos meios de produção; b) os proprietários fundiários; c) os promotores imobiliários; d) o Estado e e) os grupos sociais excluídos. Na perspectiva do autor, a complexidade da atuação particularizada de tais agentes inclui práticas generalizadas, que levam a um constante processo de estruturação e reorganização da cidade, o que acarreta contornos socioespaciais descontínuos, contraditórios e, consequentemente, desiguais. Destarte, mesmo apresentando diferenciações/conflitos em suas estratégias, a atuação de um determinado agente não ocorre de maneira isolada, ou seja, não exclui a ação dos demais, uma vez que agrega, em certas situações, denominadores comuns que, indireta e/ou diretamente, os unem em um mesmo processo de (re)produção do espaço urbano. Considerando-se tais pressupostos objetiva-se, na pesquisa, compreender a (re)produção do espaço urbano de Ituiutaba-MG sob a ótica do mercado imobiliário, contemplando os processos relacionados à comercialização de terrenos não edificados e de imóveis residenciais (casas) urbanos ofertados no principal jornal de circulação diária de Ituiutaba-MG, considerando o recorte temporal de 2000, 2005 e 2012. A escolha dos anos-base para a implementação dos levantamentos de dados/informações foi condicionada pelos seguintes fatores:

- A escolha do ano 2000 como início do recorte temporal de análise parte da ideia de que este antecede significativas transformações no espaço intraurbano de Ituiutaba-MG. Assim, propicia-se uma melhor comparação com os anos conseguintes, no que concerne à distribuição de imóveis ofertados por bairro; à diferença entre a média de preços do $\mathrm{m}^{2}$ de cada bairro em relação à média do preço da cidade e à diferenciação entre as áreas no que se refere à valorização imobiliária;

- O ano-base de 2012 constitui o período posterior à incorporação e fixação de diversos empreendimentos/projetos urbanos, compreendendo, sobretudo, investimentos subsidiados pelos governos federal e estadual no setor educacional e da moradia da população, bem como no setor terciário, pela iniciativa privada;

- Concernente à especulação de fixação de alguns desses empreendimentos, a título de exemplo, citamos a construção de uma Unidade Superior de Ensino - Universidade Federal de Uberlândia/Campus Pontal - veiculados pelos meios de comunicação impresso e digital pertinentes à escala local e regional, optamos pela escolha do ano de 2005 .

A fim de contribuir para as discussões dos temas ligados à pesquisa, tendo como locus de estudo a cidade de Ituiutaba-MG, uma questão central se colocou 
no desenvolvimento da dissertação: Qual(is) o(s) processo(s) decorrente(s) da comercialização da terra urbana, edificada ou não, em Ituiutaba-MG, no recorte temporal analisado? No encalço de respostas a este questionamento, delinearam-se as seguintes hipóteses: a) por meio dos investimentos subsidiados pelos governos federal e estadual no setor educacional e da moradia popular e pelo capital privado no setor comercial e de empreendimentos residenciais de médio e alto padrão, novas áreas foram anexadas ao perímetro urbano de Ituiutaba-MG, cunhando sua expansão horizontal; b) tais investimentos condicionaram, sob a lógica da valorização imobiliária, a seletividade entre determinadas áreas da cidade, ao longo do período, nos tipos de imóveis ofertados.

Considerando tais hipóteses e visando atingir o objetivo proposto pela pesquisa, foram realizados de modo parcial os seguintes procedimentos metodológicos: a) pesquisa teórica sobre as temáticas urbano, cidade, produção do espaço urbano, planejamento urbano e mercado imobiliário, bem como sobre a cidade de Ituiutaba, perpassando pela ótica de autores como Carlos (2008, 2013), Corrêa (2005, 2013), Rolnik (2012), Villaça (2001), Chaves (1998, 2014), Lourenço (2005), Guimarães (1990, 2010), Ferreira (2013), Mateus (2013), entre outros que se apresentaram de fundamental primazia para o trabalho; b) pesquisa documental na Biblioteca $\mathrm{Mu}$ nicipal Senador Camilo Chaves, no Museu Antropológico de Ituiutaba (MUSAI), na Galeria de Antiguidades de Ituiutaba; na Base de Dados do Instituto Brasileiro de Geografia e Estatística entre outros, com a finalidade de realizar levantamentos bibliográfico, fotográfico, cartográfico, de dados e de informações sobre a área de estudo, englobando aspectos demográficos, sociais e econômicos bem como conteúdos sobre o mercado imobiliário para o recorte temporal estabelecido.

Neste artigo, serão apresentados de modo parcial os resultados obtidos no âmbito da coleta de dados relativos à dinâmica do mercado imobiliário, uma vez que a pesquisa encontra-se em fase de desenvolvimento e não apresenta ainda resultados concretos.

\section{LOCALIZAC̣ÃO E CARACTERIZAC̣ÃO DA ÁREA DE ESTUDO}

A cidade de Ituiutaba-MG, recorte espacial deste estudo, é sede de município localizado na Mesorregião Geográfica do Triângulo Mineiro e Alto Paranaíba, mais especificamente na Microrregião ${ }^{1}$ de Ituiutaba (Figura 1). De acordo com

1 De acordo com o Instituto Brasileiro de Geografia e Estatística (IBGE), define-se como Microrregião Geográfica um conjunto de municípios, contíguos e contidos na mesma Unidade da Federação, definidos com base em características do quadro natural, da organização da produção e de sua integração. 
Nascimento e Melo (2010) e Prefeitura Municipal de Ituiutaba (2001), Ituiutaba é originário do processo de povoamento do território brasileiro ocorrido no século XIX sob o impulso da agropecuária tradicional e da chegada de vários forasteiros na região que hoje é conhecida como Triângulo Mineiro. Neste cenário, foi criado um pequeno povoado que recebeu o nome de São José do Tijuco (que deu origem, posteriormente, à cidade de Ituiutaba) por meio da formação de um patrimônio religioso marcado pela edificação da primeira capela em 1832. A partir da segunda metade do século XIX, o povoado passou a receber uma série de benfeitorias, tais como o primeiro sistema de serviço de água em 1875 e os traçados das primeiras ruas em 1883. Em 1890, já possuía 5.037 habitantes, e, em 1901, Ituiutaba foi reconhecida oficialmente como sede do município (cidade) com o nome de Vila Platina. No ano de 1915, a cidade passou a se chamar Ituiutaba, nome concedido por Delfim Moreira, que na época era o governador de Minas Gerais.

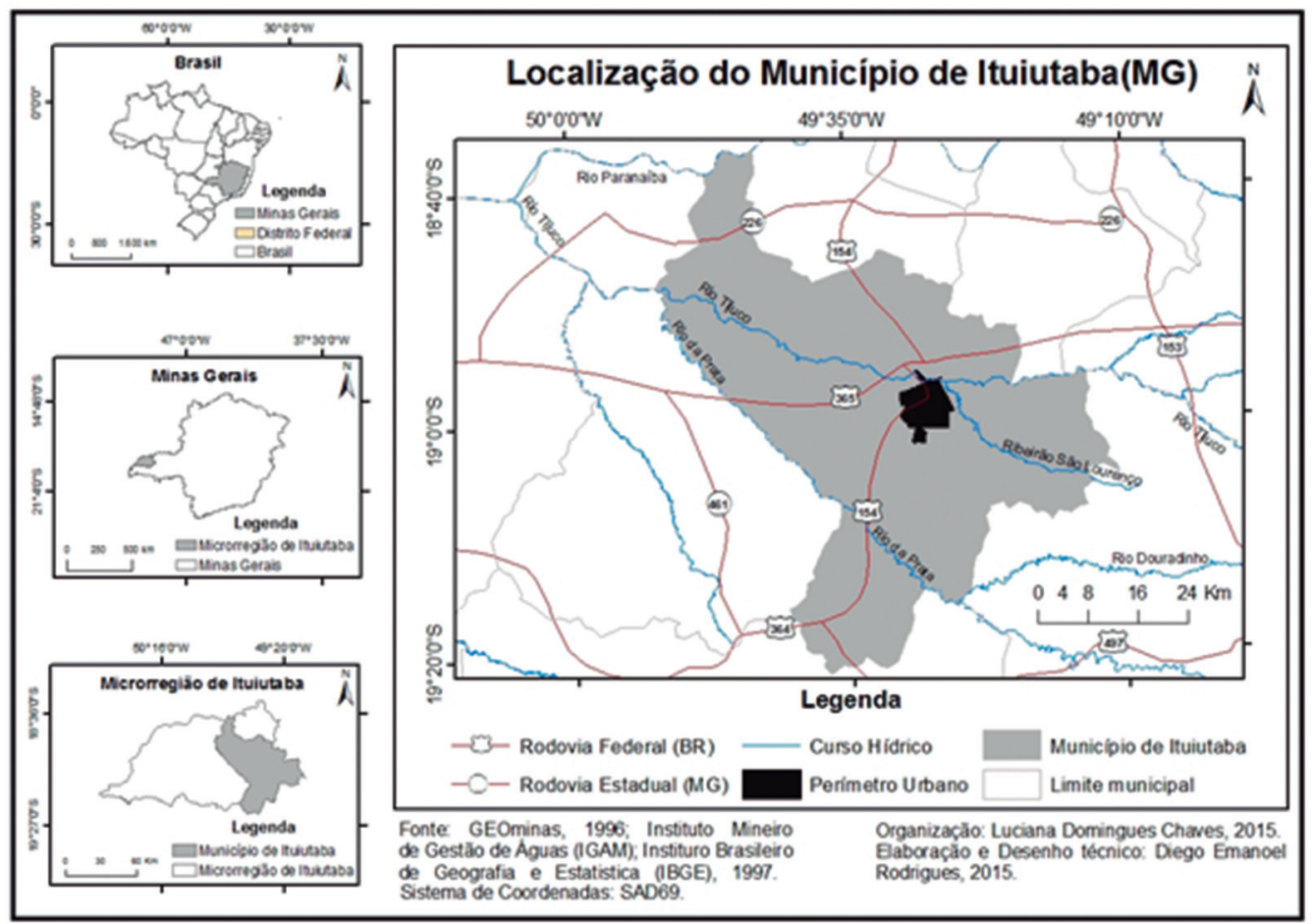

Figura 1. Microrregião de ltuiutaba-MG: localização do município e do perímetro urbano de ltuiutaba-MG, 2014.

Em linhas gerais, do ponto de vista econômico, de acordo com Prefeitura Municipal de Ituiutaba (2001), no final da década de 1930 e meados de 1940, o garimpo de ouro e de diamante no rio Tijuco se afixou como catalisador econô- 
mico em Ituiutaba-MG por aproximadamente 10 anos, atraindo aventureiros, muitos de origem nordestina. O deslocamento migratório foi alicerçado principalmente pelo fascínio acerca da pedra preciosa "Democrata" encontrada no rio Tijuco, a qual se assemelhava ao diamante "Cruzeiro do Sul".

$\mathrm{Na}$ década de 1940, Ituiutaba-MG sobressaiu pela produção de culturas agrícolas e pela produção pecuária. Segundo a Prefeitura Municipal de Ituiutaba (2001), no ano de 1943, o plantio de algodão em caroço atingiu um patamar significativo (107.400 arrobas), principalmente a partir do incentivo do industrial Baduy, o qual forneceu sementes e recursos financeiros aos lavradores, além de garantir a compra do produto, propiciando ritmo acelerado à lavoura algodoeira deste período. Outras culturas agrícolas também auferem destaque neste período tais como a produção do arroz em casca (615.960 sacos), do café beneficiado (4.080 sacos), da cana-de-açúcar (15 mil toneladas), do feijão (29.010 sacos), da mandioca (39 mil toneladas), do milho (794 mil sacos), assim como a produção pecuária com 310 mil cabeças de bovinos e 200 mil de suínos².

Nas décadas de 1960 e 1970, a rizicultura atinge seu ápice e se consolida no cenário econômico do município de Ituiutaba-MG, fazendo com que o mesmo fique conhecido nacionalmente pelo título de "Capital do Arroz" (OLIVEIRA, 2003). Assim, com base no capital originado pelo arroz,

[...] a cidade começou a melhor equipar-se com serviços de água, energia elétrica, comércio e serviços diversificados, expansão de loteamentos urbanos e novas atividades, que iriam beneficiar a população, que crescia vertiginosamente nesse período. [...] As mudanças no espaço urbano ocorreram paralelamente às do espaço rural: "levas" de trabalhadores nordestinos chegaram ao município de Ituiutaba e tornaram-se agentes transformadores do campo, responsabilizados pelas roças de arroz, milho e feijão. [...] O Capital investido no campo teve retorno na cidade de modo gradual: cresceu o numero de habitantes, residências e casas de comércios, serviços e indústrias ligadas à atividade agrícola (OLIVEIRA, 2003, p.16-17; 64).

É neste contexto de novas possibilidades que a produção da rizicultura materializa efetivas transformações tanto no que tange o espaço urbano como o rural de Ituiutaba-MG, uma vez, que seu cultivo atingiu níveis extremamente significativos nas décadas de 1960 e 1970, respectivamente 17.373 ha. e 19.526 ha., segundo Souto (2013). Entretanto, no final dos anos de 1970, a rizicultura entra em declínio e os médios e grandes proprietários rurais do município optam por se especializarem no setor pecuarista de leite e corte, e outros se adaptam aos novos seg-

2 Informações retiradas de: PREFEITURA MUNICIPAL DE ITUIUTABA (Org). O centenário de Ituiutaba. Gráfica Ituiutaba, 2001, 126 p. (Edição Especial). Não menciona os kg específicos dos sacos das produções supracitadas. 
mentos agrícolas, produzindo algodão, milho, cana-de-açúcar e soja (OLIVEIRA, 2003). Neste panorama de transformações há uma inversão dos dados em relação aos aspectos populacionais, evidenciando-se maior número de pessoas vivendo na área urbana do município conforme demonstrado na Tabela 1, fato que culminou com os projetos governamentais para a área do Cerrado, desenvolvendo o campo (grandes propriedades) e fazendo com que a população deste viesse para a cidade (êxodo rural) devido à mecanização do meio rural. Neste contexto, como nos aponta Oliveira (2003), houve a expansão de novos loteamentos urbanos, bem como emergiram novas atividades nos diferentes setores da economia para contemplar a população que crescia notoriamente neste período em Ituiutaba.

Nas décadas de 1980 e 1990, Ituiutaba-MG ganhou notoriedade no cenário regional, uma vez que recebeu empresas do setor comercial, agroindustrial e de serviços, conforme afirma Nascimento (2011). A partir dos anos 2000, especificamente de 2006, a produção canavieira torna-se proeminente para o setor econômico não apenas de Ituiutaba, mas também para o regional. Para Souto (2013), com a inserção das usinas sucroalcooleiras no âmbito da Microrregião de Ituiutaba, os pequenos e médios produtores deixaram de lado o cultivo de outros tipos de plantação agrícola, direcionando-se para a plantação da cana-de-açúcar que propiciou um crescente índice de arrendamento das terras rurais e/ou até mesmo as vendas delas para a incorporação da atividade canavieira.

Enquanto estas modificações ocorreram no campo, a cidade de Ituiutaba também passou por transformações importantes que se intensificaram nos últimos anos. Na primeira década de 2010, Ituiutaba passou por um processo marcado pela atuação do capital privado e do poder público no espaço urbano, os quais propiciaram significativas transformações na paisagem urbana, sobretudo por meio de investimentos e lançamentos de novos produtos imobiliários bastante elucidativos na reestruturação da cidade. A título de exemplo, citamos os investimentos subsidiados pelos governos federal e estadual no setor da moradia popular, os quais redesenharam os limites urbanos.

Além disso, Ituiutaba-MG tornou-se referência, principalmente no setor terciário, pela presença de instituições de ensino, equipamentos de saúde, estabelecimentos comerciais e de serviços em geral para os municípios de menor porte que estão localizados na sua área de influência, entre os quais destacam-se: Cachoeira Dourada, Capinópolis, Gurinhatã, Ipiaçu, Santa Vitória no Estado de Minas Gerais e São Simão no Estado de Goiás (NASCIMENTO; MELO, 2010).

Com uma área urbana que ultrapassa $11,8 \mathrm{~km}^{2}$ (MIRANDA; GOMES; GUIMARÃES, 2005), atualmente o mercado imobiliário de Ituiutaba-MG demonstra um grande e acelerado processo de crescimento, com investimentos em várias áreas da cidade, além de fomentos de outros setores da economia local como construção civil, instituições financeiras e investimentos por parte dos governos 


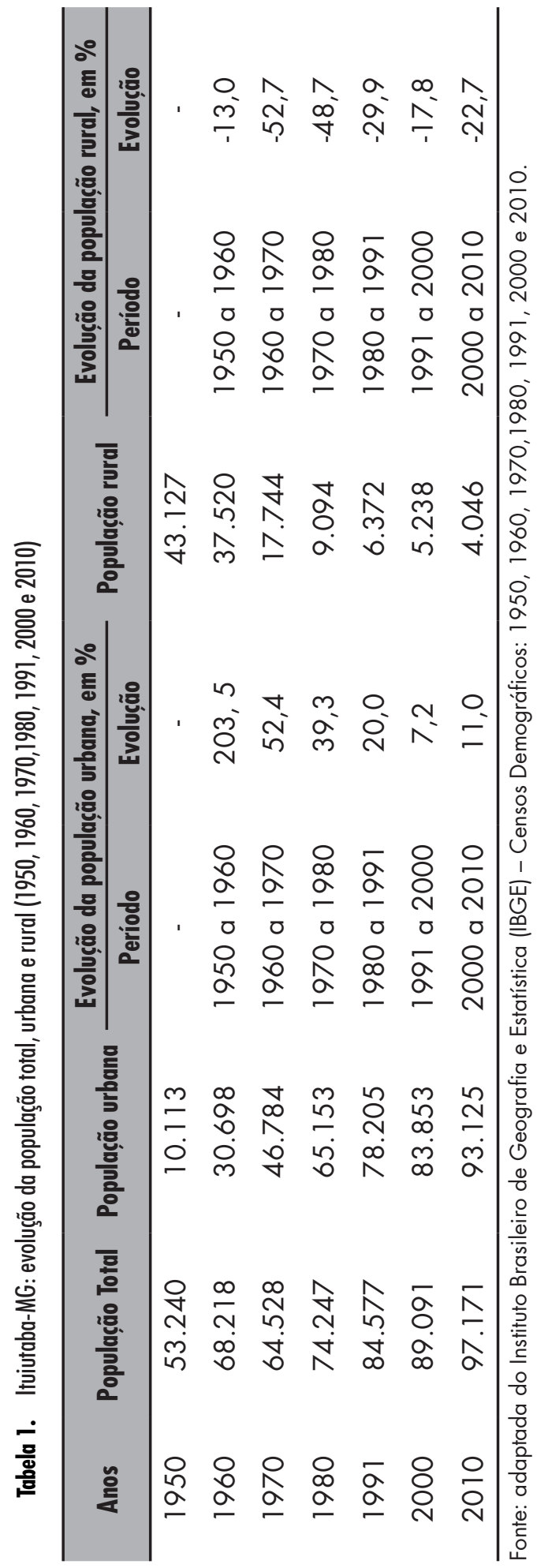


municipal, estadual e federal. Em face desses processos, o mercado imobiliário tende a intensificar ainda mais os contrastes socioeconômicos no espaço urbano de Ituiutaba-MG, aliando os interesses especulativos dos proprietários de terras urbanas não edificadas e dos imóveis residenciais (casas) urbanos.

\section{ALGUNS APONTAMENTOS TEÓRICOS}

Desde algumas décadas, as discussões acerca da produção do espaço urbano têm ganhando cada vez mais notoriedade no âmbito acadêmico acarretando o aprofundamento dos debates teóricos e a realização de estudos empíricos frente às constantes transformações que vivenciamos cotidianamente nas cidades. Sobre este tema, Corrêa (2005, p. 11), importante pesquisador do espaço urbano, destaca esse como sendo simultaneamente "fragmentado, articulado, condicionante social, cheio de símbolos e campo de lutas" e, portanto, trata-se de "um produto social, resultado de ações acumuladas através do tempo, e engrenadas por agentes que produzem e consomem espaço". Trate- se de um processo conflituoso, pois esses agentes atuam de forma diferenciada e apropriam-se do espaço de acordo com seus interesses, gerando um processo de reorganização constante deste, ou seja, um ininterrupto processo de (re)produção de forma desigual.

Em relação aos agentes produtores do espaço urbano, é indispensável esclarecer que na pesquisa em desenvolvimento, considera-se a proposição de Corrêa (2005), na qual estes são a) os proprietários dos meios de produção; b) os proprietários fundiários; c) os promotores imobiliários; d) o Estado; e) os grupos sociais excluídos. Embora a ação de todos eles se dê conjuntamente no espaço urbano, nos ateremos nesse texto à ação dos promotores imobiliários, tendo em vista o objetivo geral do trabalho em andamento.

De acordo com Corrêa (2005), por promotores imobiliários, entende-se um conjunto de agentes que realizam parcial ou totalmente as seguintes operações: a) incorporação; b) financiamento; c) estudo técnico; d) construção ou produção física do imóvel; e) comercialização ou transformação do capital-mercadoria em capital-dinheiro.

A incorporação articula os demais agentes ora citados, uma vez que pode compreender desde a aquisição da terra até a venda do imóvel para o consumidor final. Para Franco e Gondo (1991), o incorporador é aquele que com discernimento próprio financia ou obtém o financiamento da obra; procura e efetiva a compra de terrenos aptos ao desenvolvimento de empreendimentos imobiliários; idealiza, por intermédio do estudo técnico, o projeto de edificação, levando-o à aprovação pelas autoridades competentes; constrói a estrutura física do imóvel ou contrata firmas especializadas sob sua supervisão e comercializa os imóveis ou delega à imobiliária a negociação com o comprador final. 
Sem dúvida a atuação dos promotores imobiliários está diretamente ligada à valorização diferencial das áreas no interior do tecido urbano. De acordo com Campos (2011), ao selecionarem determinadas frações do espaço urbano para a implementação de empreendimentos (residencial, comercial), os promotores imobiliários conduzem o processo de formação dos sobrelucros de localização, o qual se torna conjuntamente com outros fatores (investimentos públicos/privados, infraestrutura) determinante no valor da terra urbana.

Mellazo (1993), em seu estudo sobre mercado imobiliário, acrescenta que o conjunto de fatores (localização de áreas dotadas de infraestrutura, facilidade de acesso, equipamentos de usos coletivos, presenças de áreas verdes, entre outros) é que distingue qualitativamente uma parcela do solo, dando-lhe certo valor e diferenciando-o em relação à aglomeração na qual se insere. A partir dessas concepções é possível afirmar que a cidade é (re)produzida não como um todo, ou seja, de maneira homogênea, mas como partes que se formam em tempos diferentes.

Contribuindo com a discussão, Villaça (2001), importante pesquisador do espaço intraurbano, chama atenção para o fato de a terra urbana permitir maior ou menor valorização pelo acesso que sua localização propicia a todo sistema urbano, a toda a cidade. Usa como exemplo os lotes não edificados, os quais têm seu valor aumentado tanto por investimentos privados e/ou públicos e por infraestrutura em seu entorno quanto por sua localização.

Outra contribuição importante é oferecida por Santos (2007), que revela a importância da localização bem como da acessibilidade, ou seja, não se trata de pagar pela terra urbana, mas por sua localização. Estudos realizados por Carlos (2013) reforçam a localização, como ponto de partida para a determinação do preço do solo urbano, atrelada a outros fatores como: acesso aos lugares ditos privilegiados; acesso a infraestrutura básica (sistemas de serviços urbanos, transporte e comunicação); privacidade e, secundariamente, fatores vinculados às características físicas como relevo, dimensões da área tendem a auferir lucro no valor da terra, como também podem causar queda nos preços, devido ausência parcial e/ou total dos mesmos.

Assim, para fechar esse texto sem, contudo, concluir a análise e as discussões, aponta-se que ao analisar a dinâmica da (re)produção do espaço urbano e a atuação dos seus agentes produtores, é possível apreender como a sociedade intrínseca ao capital se apropria deste espaço conforme suas especificidades.

\section{DADOS RELATIVOS À DINÂMICA DO MERCADO IMOBILIÁRIO}

A fim de privilegiar a dimensão econômica da (re)produção do espaço urbano de Ituiutaba-MG, destacando, principalmente, as estratégias de valoriza- 
ção/desvalorização de determinadas áreas e as diferenças nos movimentos do preço ofertado total e por $\mathrm{m}^{2}$ em reais, optamos por uma única fonte de dados, fundamentada em metodologia desenvolvida nas pesquisas sobre a temática no âmbito da Rede de Pesquisadores sobre Cidades Médias (ReCiMe): anúncios em classificados de jornais. Dessa maneira, coletamos as informações nos anún$\operatorname{cios}^{3}$ de classificados do principal jornal de circulação diária de Ituiutaba-MG, o “Jornal do Pontal: um diário a serviço da região", relativas à dinâmica do mercado imobiliário, para o período analisado. Para tanto, selecionamos anúncios um sábado por mês. Tendo em conta que o(s) imóvel(is) pode(m) levar meses para ser(em) vendido(s), uma abrangência temporal maior poderia resultar em um significativo volume de ofertas repetidas do mesmo imóvel - o que julgou-se desnecessário.

A metodologia ${ }^{4}$ empregada consistiu na extração e transcrição dos anúncios de venda de terrenos não edificados e imóveis residenciais (casa), publicados de janeiro a dezembro de cada ano, abarcando as variáveis disponíveis (descritas no Quadro 1). Convém destacar que as variáveis setor e preço do $\mathrm{m}^{2}$ (ambas destacadas em cinza) não se encontravam diretamente nos anúncios, sendo acrescidas no processo de tabulação dos dados.

Nosso levantamento resultou em um volume total de 787 ofertas tabuladas em planilhas do software Excel@ compostas por linhas e colunas. Em cada linha foi disposto um anúncio e em cada coluna, as suas informações particulares. Este quantitativo total não compreendeu os anúncios repetidos ao longo do(s) mês(es). Esta situação de repetição, que poderia sugerir um cenário irreal para determinadas áreas da cidade, foi contornada com a exclusão dos anúncios duplicados, o que demandou uma estreita padronização no momento da digitação dos dados.

Quadro 1. Variáveis coletas e estrutura do banco de dados dos anúncios imobiliários

\begin{tabular}{cccc}
\hline $\mathbf{N}^{0}$ & Imóvel & Variável & Descrição \\
\hline 1 & Terreno e Casa & Dia & Dia da publicação do anúncio \\
2 & Terreno e Casa & Mês & Mês da publicação do anúncio \\
3 & Terreno e Casa & Ano & Ano da publicação do anúncio \\
\hline
\end{tabular}

3 Entende-se por anúncio cada oferta individual de imóvel não edificado divulgado pelas imobiliárias anunciantes.

4 Melazzo (2010) traz importantes e atuais considerações metodológicas voltadas a este tipo de pesquisa aplicada em cidades de porte médio no âmbito da Rede de Pesquisadores sobre Cidades Médias (ReCiMe). 


\begin{tabular}{|c|c|c|c|}
\hline $\mathbf{N}^{0}$ & Imóvel & Variável & Descrição \\
\hline 4 & Terreno e Casa & $\begin{array}{l}\text { Imobiliária/ } \\
\text { corretor(a) }\end{array}$ & $\begin{array}{c}\text { Nome da Imobiliária/corretor(a) anun- } \\
\text { ciante }\end{array}$ \\
\hline 5 & Terreno e Casa & Localização & Bairro ao qual se refere o anúncio \\
\hline 6 & Terreno e Casa & Setor & Setor urbano correspondente ao bairro \\
\hline 7 & Terreno e Casa & Preço & Preço total ofertado em reais $(R \$)$ \\
\hline 8 & Terreno e Casa & $\begin{array}{l}\text { Área total do } \\
\text { imóvel }\end{array}$ & Dimensão total do imóvel $\left(\mathrm{m}^{2}\right)$ \\
\hline 9 & Terreno & Preço do $\mathrm{m}^{2}$ & Preço do $\mathrm{m}^{2}$ do terreno em reais $(\mathrm{R} \$$ ) \\
\hline 10 & Casa & Área construída & Área útil $\left(\mathrm{m}^{2}\right)$ \\
\hline 11 & Casa & Cômodos & $\begin{array}{l}\text { A residência comercializada dispõe de: } \\
\text { quarto, suíte, sala, copa, cozinha, banhei- } \\
\text { ro social, despensa/cômodo de despejo, } \\
\text { varanda, garagem e área de serviço. }\end{array}$ \\
\hline
\end{tabular}

Fonte: adaptado de MELLAZO (2010).

\section{RESULTADOS E CONCLUSÕES}

A partir da tabulação e da organização dos dados em planilhas do software Excel®, e com o apoio da bibliografia estudada, notou-se de maneira genérica mudanças na (re)produção do espaço urbano de Ituiutaba-MG, ligadas a inter-relação dos fatores a) localização dos anúncios; b) preço ofertado em reais e c) seletividade espacial, de modo a destacar determinadas áreas da cidade no tocante a potencial valorização imobiliária. Por fim, mas não menos importante, convém reforçar que no presente artigo explanou-se de maneira genérica alguns apontamentos acerca da coleta de dados relativa à dinâmica do mercado imobiliário. Espera-se com a finalização da pesquisa atingir o objetivo proposto pela mesma, de modo a contribuir com o debate acerca da (re)produção do espaço urbano, tendo, como exemplo, a cidade de Ituiutaba-MG.

\section{AGRADECIMENTOS}

Agradeço à Coordenação de Aperfeiçoamento de Pessoal de Nível Superior pela concessão da bolsa de Mestrado.

\section{REFERÊNCIAS}

CAMPOS, P. R. O preço da terra urbana e moradia de baixo custo. In: MENDONÇA, J. G. de; COSTA, H. S. de M. (Org.). Estado e Capital Imobiliário: convergências atuais 
na produção do espaço urbano brasileiro. Belo Horizonte: C/Arte, 2011. p. 63-79. CARLOS, A. F. A. A cidade. 9. ed. São Paulo: Contexto, 2013. (Coleção Repensando a Geografia).

. A (re)produção do espaço urbano. São Paulo: Edusp, 2008.

CHAVES, C. Caiapônia: romance da terra e do homem do Brasil Central. 3. ed. Ituiutaba: [s. n.], 1998.

. Produção do espaço urbano e mercado imobiliário: um estudo de caso de Ituiutaba - MG. 2014. 81 f. Trabalho de conclusão de curso (Graduação em Geografia) - Faculdade de Ciências Integradas do Pontal, Universidade Federal de Uberlândia, Ituiutaba, 2014.

CORRÊA, R. L. O espaço urbano. 4. ed. São Paulo: Ática, 2005. . Segregação socioespacial e centralidade urbana. In: VASCONCELOS, P. de A.; CORRÊA, R. L. (Org.). A cidade contemporânea: segregação espacial. São Paulo: Contexto, 2013. p. 39-59.

FRANCO, J. N.; GONDO, N. Incorporações imobiliárias. 3. ed. São Paulo: Revista dos Tribunais. 1991.

FERREIRA, L. de F. Programa Minha Casa Minha Vida em Ituiutaba (MG): uma análise dos conjuntos habitacionais Buritis, Canaã I e Canaã II. 2013. 90 f. Trabalho de conclusão de curso (Graduação em Geografia) - Faculdade de Ciências Integradas do Pontal, Universidade Federal de Uberlândia, Ituiutaba, 2013.

GUIMARÃES, E. N. Formação e desenvolvimento econômico do Triângulo Mineiro: integração nacional e consolidação regional. Uberlândia: EDUFU, 2010.

. Infra-estrutura pública e movimento de capitais: a inserção do Triângulo Mineiro na divisão inter-regional do trabalho. 1990. 224 f. Dissertação (Mestrado em Desenvolvimento e Planejamento Regional) - Universidade Federal de Minas Gerais, Belo Horizonte, 1990.

LOURENÇO, L. A. B. A oeste das minas: escravos, índios e homens livres numa fronteira oitocentista, Triângulo Mineiro (1750-1861). Uberlândia: Edufu, 2005.

MATEUS, R. A dinâmica da agricultura no cerrado: do apogeu do arroz à modernização do campo na região de Ituiutaba (MG) - 1946-1974. 2013. 84 f. Trabalho de conclusão de curso (Bacharelado em História) - Faculdade de Ciências Integradas do Pontal, Universidade Federal de Uberlândia, Ituiutaba, 2013.

MELLAZO, E. S. Mercado imobiliário, expansão territorial e transformações intraurbanas: o caso de Presidente Prudente-SP. 1993. 141 f. Dissertação (Mestrado em Planejamento Urbano e Regional) - Instituto de Pesquisa e Planejamento Urbano e Regional, Universidade do Rio de Janeiro, Rio de Janeiro, 1993.

. Dinâmica imobiliária e processos de estruturação intra-urbana em cidades de porte médio: hipóteses e propostas de trabalho. In.: ENCONTRO NACIONAL DOS GEÓGRAFOS CRISE, PRÁXIS E AUTONOMIA, 16, 2010, Porto Alegre. Anais... Porto Alegre, 2010. p. 1-11. 
MIRANDA, E. E. de; GOMES, E. G.; GUIMARÃES, M. Mapeamento e estimativa da área urbanizada do Brasil com base em imagens orbitais e modelos estatísticos. Campinas: Embrapa Monitoramento por Satélite, 2005. Disponível em: <http://www. urbanizacao.cnpm.embrapa.br>. Acesso em: 7 jan. 2014.

NASCIMENTO, P. A. G. do. Dinâmica da produção do espaço urbano e habitação popular na cidade de Ituiutaba (MG): uma análise dos conjuntos habitacionais Jardim Europa, Residencial Carlos Dias Leite e Residencial Tupã Ituiutaba (MG). 2011. 103 f. Trabalho de conclusão de curso (Graduação em Geografia) - Faculdade de Ciências Integradas do Pontal, Universidade Federal de Uberlândia, Ituiutaba, 2011.

NASCIMENTO, P. A. G. do; MELO, N. A. Ituiutaba (MG): os agentes econômicos e a (re)estruturação da cidade na rede urbana regional. Horizonte Científico. Uberlândia, v. 4, n. 1, p. 1-35, 2010.

OLIVEIRA, B. S. de. Ituiutaba (MG) na rede urbana tijucana: (re)configurações sócioespaciais no período de 1950 a 2000. 2003. 204 f. Dissertação (Mestrado em Geografia) - Instituto de Geografia, Universidade Federal de Uberlândia, Uberlândia, 2003.

PREFEITURA MUNICIPAL DE ITUIUTABA (Org.). O centenário de Ituiutaba. Ituiutaba: Gráfica Ituiutaba, 2001. 126 p. (Edição Especial).

ROLNIK, R. O que é cidade. 4. ed. São Paulo: Brasiliense, 2012.

SANTOS, M. O espaço do cidadão. São Paulo: Nobel, 2007.

SOUTO, T. S. Caracterização da produção agropecuária do município de Ituiutaba-MG no período de 1960 a 2011. 2013. 101 f. Trabalho de conclusão de curso (Graduação em Geografia) - Faculdade de Ciências Integradas do Pontal, Universidade Federal de Uberlândia, Ituiutaba, 2013.

VILLAÇA, F. Espaço intra-urbano no Brasil. 2. ed. São Paulo: Studio Nobel/FAPESP, 2001. 